DOI: https://doi.org/10.24127/ajpm.v9i3.2900

\title{
ETNOMATEMATIKA UNTUK SISWA SEKOLAH MENENGAH: EKSPLORASI KONSEP-KONSEP GEOMETRI PADA BUDAYA SUKU BOTI
}

\author{
Wilfridus Beda Nuba Dosinaeng ${ }^{1}$, Meryani Lakapu², Yohanes Ovaritus Jagom³, \\ Irmina Veronika Uskono ${ }^{4}$, Samuel Igo Leton ${ }^{5}$, Kristoforus Djawa Djong ${ }^{6}$ \\ 1,2,3,4 Universitas Katolik Widya Mandira, Kupang, Indonesia \\ E-mail: $\quad$ wilfridusdosinaeng@gmail.com ${ }^{1)}$ \\ $\underline{\text { meryanilakapu@gmail.com }}^{2)}$ \\ kraengyovanmgr@gmail.com $^{3)}$ \\ veniuskono@gmail.com ${ }^{4}$ \\ letonsamuel@gmail.com ${ }^{5)}$ \\ djongdeflores@ gmail.com $^{\text {6) }}$
}

Received 29 June 2020; Received in revised form 11 September 2020; Accepted 17 September 2020

\begin{abstract}
Abstrak
Suku Boti sebagai salah satu suku tertua di pulau Timor, Nusa Tenggara Timur yang kaya akan warisan budaya. Keunikan budaya Boti perlu dijaga dan dilestarikan karena merupakan salah satu budaya asli Indonesia. Penelitian ini adalah penelitian kualitatif berdesain etnografi yang bertujuan untuk mengeksplorasi unsur-unsur geometri yang terdapat dalam budaya suku Boti. Subjek dalam penelitian ini yaitu masyarakat suku Boti Dalam yang masih tertutup terhadap budaya modern dan menjalankan tradisi budaya Boti dalam kehidupan sehari-hari. Objek yang diteliti dalam penelitian ini yaitu lopo, tup mahae, tobe, dan sene. Teknik analisis data yang digunakan dalam penelitian ini yaitu analisis taksonomi. Hasil penelitian menunjukkan bahwa konsep-konsep geometri meliputi aksioma titik, garis, dan bidang, konsep garis singgung, konsep luas dan volume bangun datar, konsep luas dan volume bangun ruang, serta konsep kekongruenan. Selain itu, kemampuan-kemampuan matematis seperti kemampuan representasi, kemampuan visual spasial, kemampuan koneksi, dan kemampuan pemecahan masalah dapat dikembangkan berdasarkan unsur-unsur geometris pada budaya suku Boti. Hasil eksplorasi ini dapat digunakan oleh para guru matematika untuk mengembangkan pembelajaran geometri di kelas berbasis budaya Boti.
\end{abstract}

Kata kunci: Etnomatematika; geometri; lopo; tup mahae dan tobe; sene.

\begin{abstract}
Boti as one of the oldest tribes on the Timor Island, East Nusa Tenggara, has a lot of cultural heritage. The uniqueness of Boti culture needs to be preserved because it is one of Indonesia's original cultures. This is a qualitative research with ethnographic design which aimed to explore the geometry concepts contained in Boti culture. The subject of this research is the Boti Dalam society which still closed to modern culture and maintain the Boti cultural traditions in daily life. The objects discussed in this research are lopo, tup mahae, tobe, and sene. The data analysis technique used in this research is taxonomic analysis. The results showed that the concepts of geometry covering the axioms of points, lines, and fields, tangent concept, the concept of area and volume of flat shapes, the concept of area and volume of space builds, and the concept of concordance. In addition, mathematical abilities such as representation, visual spatial ability, connection ability, and problem solving ability can be developed based on geometric culture of the Boti Tribe. The results of this exploration can be used by mathematics teachers to develop geometry learning in Boti culture-based classes.
\end{abstract}

Keywords: Ethnomathematics; geometry; lopo; tup mahae and tobe; sene.

This is an open access article under the Creative Commons Attribution 4.0 International License 
DOI: https://doi.org/10.24127/ajpm.v9i3.2900

\section{PENDAHULUAN}

Matematika adalah salah satu mata pelajaran wajib mulai dari jenjang Sekolah Dasar sampai Sekolah Menengah Atas. Hal ini dikarenakan matematika telah menjadi bagian dalam hidup keseharian manusia, bahkan sejak zaman dahulu, banyak aktivitas manusia yang tanpa disadari mengandung unsurunsur matematis di dalamnya (Muhtadi, dkk, 2017). Unsur-unsur ini melekat baik dalam kehidupan praktis ataupun sebagai dasar dalam mempelajari ilmuilmu lainnya.

Geometri sebagai cabang dari ilmu matematika telah dikenal oleh manusia sejak zaman dahulu kala. Perkembangan geometri tidak terlepas dari budaya di mana konsep tersebut berkembang. Masyarakat Mesir Kuno menggunakan geometri untuk menentukan batas-batas tanah di sekitar Sungai Nil (Purnama \& Rohmah, 2018). Di dalam Sulba Sutras terungkap bahwa sejak sebelum masehi masyarakat India telah mengenal metode lingkaran yang luasnya menghampiri persegi yang diberikan. Di Indonesia sendiri, unsurunsur geometri telah terintegrasi dalam kehidupan masyarakat Indonesia secara luas. Sebagai contoh, pada budaya masyarakat Sunda banyak terkandung unsur-unsur geometri seperti panjang (jeungkal, depa, siku, lengkah), lebar (ramo, jempol, tampah), tinggi (curuk, tangtung, mumuncangan, bitis, cangkeng, dada, sirah), dan volume (kulak, dolak, bakul, gantang, cangkir, keupeul) (Abdullah, 2017). Unsur-unsur geometri juga terintegrasi pada motifmotif kerawang seperti matanelo, pucuk rebung, puter tali, emun berkune, peger,emun berangkat, rante, emun beriring dan cucuk pengong (Yustinaningrum, Nurliana, \& Rahmadhani, 2018). Konsep geometri lainnya seperti transformasi geometri terintegrasi dalam anyaman bambu yang dibuat oleh komunitas Muntuk (Maryati \& Prahmana, 2019). Hal ini menunjukkan bahwa konsep geometri pada dasarnya telah menjadi bagian dari kebudayaan Bangsa Indonesia.

Mempelajari perkembangan konsep geometri dalam budaya dan kaitannya dengan geometri sebagai ilmu pengetahuan dapat dilakukan melalui etnomatematika. Dari segi susunan katanya, etnomatematika terdiri dari dua kata yaitu etno- yang merujuk pada budaya dalam pengertian luas, meliputi segala sesuatu terkait budaya seperti nilai-nilai, norma, artefak-artefak budaya, dan -matematika yang merujuk pada pengetahuan-pengetahuan matematis seperti mengukur, membilang, membandingkan, mengurutkan, dan sebagainya (Ambrosio, 1985; Utami, Sayuti, \& Jailani, 2019). Secara umum, D'Ambrosio menjelaskan etnomatematika sebagai matematika yang dipraktikkan oleh kelompok budaya tertentu (Ambrosio, 1985). Melalui pendekatan etnomatematika, cara berpikir masyarakat yang menghasilkan matematika diungkap sehingga menjembatani antara unsurunsur matematis yang ada dalam budaya dan konsep-konsep matematika sekolah (Maryati \& Prahmana, 2019; Yustinaningrum et al., 2018).

Sebagai bagian dari kurikulum matematika sekolah, penerapan etnomatematika dalam pembelajaran geometri dapat meningkatkan kemampuan kognitif, afektif, psikomotor siswa menggunakan budaya mereka sendiri yang bersifat unik (Rachmaniah Mirza Hariastuti, Budiarto, \& Manuharawati, 2019). Dari sisi kognitif, etnomatematika sejalan dengan teori konstruktivisme Vygotsky yaitu pengetahuan dasar tentang 
matematika diperoleh seseorang dari konsep-konsep matematika dalam budaya, kemudian berkembang dan menjadi solid melalui pembelajaran matematika di sekolah (Fouze \& Amit, 2018). Dari segi afektif, pembelajaran geometri berbasis etnomatematika akan meningkatkan semangat nasionalisme dan meningkatkan motivasi siswa (Zaenuri, Dwidayati, \& Suyitno, 2019). Pembelajaran matematika berbasis budaya dapat membantu siswa untuk lebih mengenal dan mencintai budayanya sendiri (Dosinaeng, 2017). Sedangkan dari segi psikomotor, melalui etnomatematika, kemampuan psikomotor seseorang dapat ditingkatkan dan mempengaruhi pengembangan intelektualnya (Supriadi, Susilawati, \& Tristyanto, 2019).

Suku Boti sebagai salah satu suku tertua di pulau Timor, Nusa Tenggara Timur kaya akan warisan budaya. Suku Boti tinggal di Kecamatan Kie, Kabupaten Timor Tengah Selatan dan terbagi atas dua bagian yaitu suku Boti Dalam dan suku Boti Luar. Di antara keduanya, suku Boti Dalam lah yang masih memepertahankan eksistensi budayanya dan menutup diri dari pengaruh budaya luar.

Keunikan budaya Boti perlu dijaga dan dilestarikan karena merupakan salah satu budaya asli Indonesia. Sudah banyak penelitian yang dilakukan berkaitan dengan suku Boti. Andung \& Nope (2017) meneliti tentang seni pertunjukan tradisional bonet sebagai media komunikasi masyarakat Boti. Nuban, Hartiwiningsih, \& Jamin (2017) meneliti tentang aspek hukum adat suku Boti. Suminar (2018) meneliti tentang persepsi suku Boti terhadap lingkungan sekitarnya. Sandiningtyas \& Wiyono (2018) mengkaji pendidikan berbasis budaya lokal suku Boti yang terintegrasi dalam mata pelajaran Muatan Lokal maupun ekstrakurikuler. Dari sekian banyak penelitian yang telah dilakukan, belum ada yang berfokus pada aspek etnomatematika dari suku Boti.

Pembelajaran geometri berbasis budaya suku Boti akan memberikan pengalaman belajar yang berbeda bagi para siswa. Penelitian ini bertujuan untuk mengeksplorasi unsur-unsur geometris yang terkandung dalam budaya suku Boti. Berdasarkan aspekaspek yang ditemukan dari penelitian ini, para guru dapat mengembangkan pembelajaran geometri berbasis budaya suku Boti.

\section{METODE PENELITIAN}

Penelitian ini adalah suatu penelitian kualitatif berdesain etnografi. Penelitian diawali dengan menganalisis dokumen-dokumen terkait suku Boti untuk memperoleh gambaran umum tentang budaya Boti. Dari analisis dokumen ini, suku Boti Dalam, khususnya Usif Boti (Raja Boti) dan para tetua suku Boti dipilih sebagai subjek penelitian sebab masih menjaga dan menjalankan budaya Boti sampai sekarang.

Setelah subjek penelitian terpilih, observasi dan wawancara mendalam kemudian dilakukan di lokasi kegiatan yaitu daerah Boti Dalam. Observasi dilakukan pada artefak-artefak suku Boti yang banyak mengandung unsurunsur geometris. Selain itu, wawancara bersama subjek penelitian juga dilakukan untuk memperoleh informasi lebih mendalam tentang artefak-artefak suku Boti tersebut.

Berdasarkan langkah-langkah penelitian di atas maka secara umum ada dua instrumen yang digunakan dalam penelitian ini yaitu peneliti sebagai instrumen utama dan instrumeninstrumen pendukung lainnya. Ghony \& 
Almanshur (2014) menjelaskan bahwa dalam penelitian kualitatif, penelitilah yang berperan sebagai instrumen utama sebab dapat bersikap fleksibel dan adaptif, serta dapat menggunakan seluruh indra yang dimilikinya untuk memahami sesuatu. Sedangkan, instrumen pendukung yang digunakan dalam penelitian ini yaitu pedoman observasi yang digunakan sebagai panduan dalam melakukan observasi pada artefak-artefak budaya yang terdapat di suku Boti dan pedoman wawancara yang digunakan untuk mewawancarai subjek penelitian.

Teknik analisis data yang digunakan dalam penelitian ini yaitu analisis taksonomi. Analisis taksonomi dilakukan untuk mengungkap unsurunsur geometris dalam artefak budaya Boti yang dapat digunakan dalam pembelajaran matematika di sekolah. Analisis didasarkan pada hasil wawancara bersama subjek penelitian dan observasi pada artefak-artefak budaya suku Boti meliputi lopo, tup mahae dan tobe, serta sene dengan difokuskan pada kesamaan antara unsur-unsur matematis dalam artefakartefak budaya tersebut dengan konsepkonsep geometri yang dipelajari di sekolah.

\section{HASIL DAN PEMBAHASAN}

Lopo

Lopo merupakan salah satu rumah tradisional suku Boti yang melekat dengan kehidupan sehari-hari masyarakatnya. Lopo Boti menyimbolkan kaum lelaki suku Boti, biasanya dibangun di bagian depan rumah tinggal masyarakat Boti. Sebagai rumah tradisional, Lopo Boti memiliki fungsi ganda yaitu sebagai tempat berkumpul dan sebagai tempat menyimpan makanan. Bentuk dari Lopo Boti dapat dilihat pada Gambar 1.

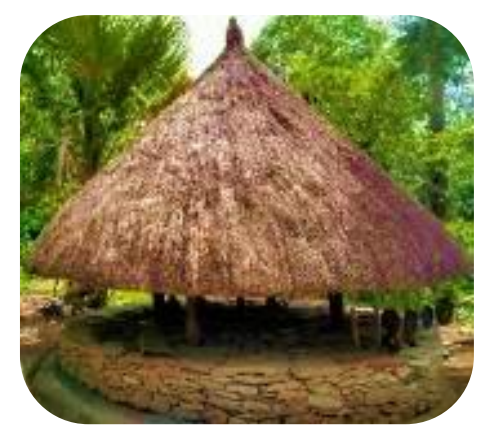

Gambar 1. Lopo Boti di kawasan Sonaf Boti.

Sebagai bangunan yang berada di Kawasan istana kerajaan Boti, Lopo di Sonaf Boti atau kediaman Raja Boti (Gambar 1) lebih berfungsi sebagai tempat berkumpulnya masyarakat Boti untuk mendengar arahan dari Usif Boti (Raja Boti) dan tempat diselenggarakannya berbagai ritual adat yang dipimpin langsung oleh Usif Boti. Ciri khas dari Lopo Boti yaitu memiliki tiang utama di bagian tengah yang menyimbolkan Usif Boti sebagai pemimpin dan penghubung antara masyarakat Boti dan para Dewa yang disebut Uis Neno dan Uis Pah. Hal ini berbeda jika dibandingkan dengan bentuk-bentuk lopo dari daerah lain di Timor Tengah Selatan seperti lopo di Kawasan Benteng None dan lopo di Desa Nusa yang tidak memiliki tiang utama.

Secara umum Lopo Boti terbagi atas tiga bagian utama yaitu: (i) bagian dasar, (ii) bagian badan, dan (iii) bagian atap lopo. Bagian dasar Lopo Boti dibentuk dari batu-batu yang disusun secara melingkar ke atas dengan ukuran tinggi yang ditentukan oleh Usif Boti. 

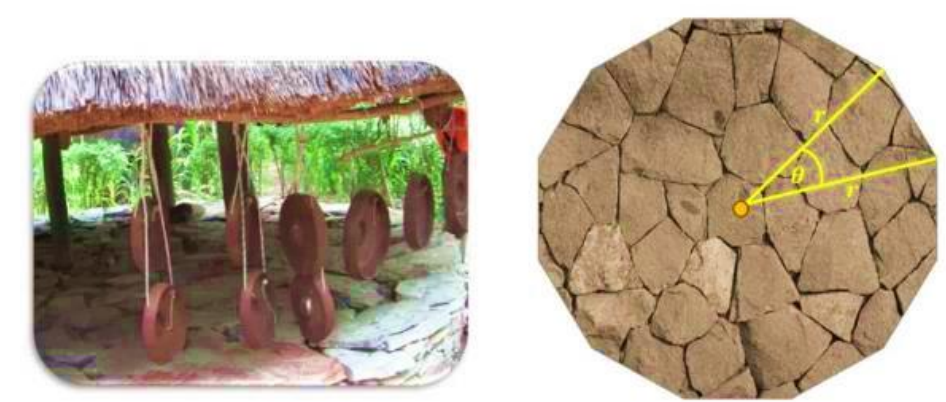

Gambar 2. Pendekatan luas segitiga pada dasar Lopo Boti.

\begin{abstract}
Bentuk dasar Lopo Boti mengintegrasikan konsep geometri khususnya konsep tabung dengan permukaan sisi atasnya berbentuk lingkaran. Jika diperhatikan, sisi atas dari dasar lopo sebenarnya tidak berbentuk lingkaran mulus namun berupa gabungan $n$ buah segitiga. Hal ini dikarenakan dasar lopo dibentuk dari batu-batu pipih yang disusun melingkar. Semakin banyak segitiga pada tepi dasar lopo maka permukaan atas dari dasar lopo semakin menyerupai bentuk lingkaran (Gambar 2). Dengan mengamati bentuk ini, menggunakan konsep limit tak hingga diperoleh:
\end{abstract}

$$
\begin{aligned}
L_{\text {sisi atas dasar lopo }}= & \lim _{n \rightarrow \infty} n \cdot \frac{1}{2} r^{2} \operatorname{Sin} \theta \\
= & \lim _{n \rightarrow \infty} \frac{\frac{\pi}{n}}{\frac{\pi}{n}} n . \\
& \frac{1}{2} r^{2} \operatorname{Sin} \theta \\
= & \lim _{n \rightarrow \infty} \cdot \frac{\pi}{\frac{2 \pi}{n}} r^{2} \operatorname{Sin} \theta \\
= & \lim _{n \rightarrow \infty} \cdot \frac{\pi}{\theta} r^{2} \operatorname{Sin} \theta
\end{aligned}
$$

$$
\begin{aligned}
& =\pi r^{2} \lim _{n \rightarrow \infty} \cdot \frac{\sin \theta}{\theta} \\
& =\pi r^{2}
\end{aligned}
$$

Karena berbentuk tabung maka konsep luas permukaan tabung juga terintegrasi pada dasar lopo. Luas permukaan dasar lopo dapat dicari dengan menghitung luas selimut dasar lopo ditambah dengan selisih antara luas sisi atas dari dasar lopo dengan luas area yang ditembusi oleh badan lopo yang terdiri dari satu tiang utama dan empat tiang penopang atap lopo yang juga berbentuk tabung (Gambar 3). Melalui bentuk ini, siswa dapat belajar tentang cara menghitung luas suatu bangun datar yang beberapa bagiannya diarsir. Mereka perlu mengetahui luas dari setiap area yang diketahui dan mengombinasikannya untuk memperoleh luas area yang diminta. Kemampuan ini penting untuk dimiliki siswa karena sejatinya matematika adalah pemecahan masalah (problem solving) dan bukan hanya menghitung.
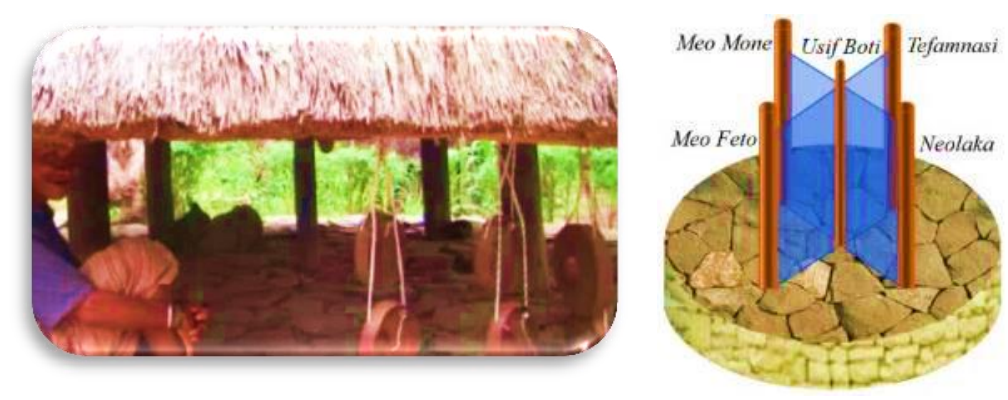

Gambar 3. Badan Lopo Boti. 
DOI: https://doi.org/10.24127/ajpm.v9i3.2900

Bagian badan lopo terdiri dari 5 buah tiang berbentuk tabung; 1 tiang utama yang menyimbolkan Usif Boti terletak di bagian tengah lopo dan menghubungkan bagian dasar sampai puncak Lopo Boti, sedangkan 4 tiang lainnya di empat penjuru mata angin dengan diameter yang lebih besar dari tiang utama berfungsi sebagai penopang bagian atap dan menyimbolkan 4 Panglima Kerajaan Boti yaitu Meo Mone, Meo Feto, Neolaka, dan Tefamnasi yang menjaga Usif Boti.

Posisi kelima tiang pada badan lopo mengintegrasikan aksioma garis dan bidang yaitu di antara dua garis sejajar dapat dibentuk suatu bidang. Pada Gambar 3 dapat dilihat bahwa suatu bidang dapat dibentuk di antara tiang Usif Boti dan salah satu tiang panglima. Selain itu, posisi kelima tiang ini juga mengintegrasikan aksioma garis dan bidang lainnya, yaitu perpotongan dua buah bidang yang tidak sejajar (misalnya perpotongan bidang yang dibentuk oleh tiang Meo Feto dan tiang Tefamnasi dengan bidang yang dibentuk oleh tiang Meo Mone dan Neolaka) akan membentuk suatu garis (tiang Usif Boti).

Bagian ketiga yaitu atap lopo berbentuk selimut kerucut dan terbagi atas dua bagian yaitu bagian luar yang terbuat dari alang-alang dan bagian dalam yang berbentuk kerangka untuk mengikat alang-alang di bagian luar. Konstruki dari atap Lopo dapat dilihat pada Gambar 4.

Jika diperhatikan, kerangka dari atap Lopo terdiri dari rusuk-rusuk yang disebut suaf yang salah satu ujungnya berpotongan di puncak lopo dan lingkaran-lingkaran yang tersusun sejajar secara vertikal dan berpotongan dengan badan suaf pada jarak-jarak tertentu. Suaf pada lopo harus berjumlah genap, ada yang berjumlah $28,30,32$,
34, dan seterusnya (suaf pada Lopo Boti di Gambar 1 berjumlah 44 buah). Hal ini dikarenakan suku Boti percaya bahwa jika suaf berjumlah ganjil maka hal yang buruk akan terjadi pada keluarga pemilik lopo tersebut.

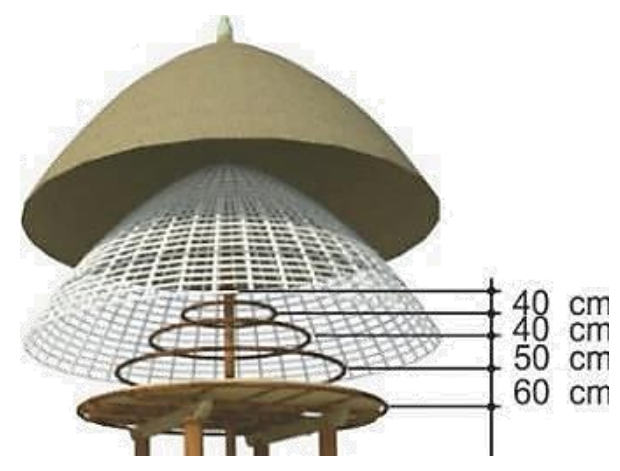

Gambar 4. Struktur atap Lopo Boti.

Dalam pembuatan atap, biasanya tiang utama dan lingkaran loteng pada atap dijadikan sebagai patokan. Dari puncak atap, suaf-suaf dihubungkan dengan bagian sisi loteng yang berbentuk lingkaran sehingga menyerupai kerangka kerucut. Selanjutnya, untuk menjaga posisi suaf agar tidak bergeser sekaligus tempat pengikat alang-alang untuk sisi bagian luar, dibentuk 25 lingkaran yang berpotongan dengan suaf-suaf. Selain 25 lingkaran tersebut, Pada Gambar 4 dapat dilihat bahwa terdapat 4 lingkaran lainnya yang sejajar dengan atap lopo sebagai pengikat bagian atap dan badan lopo.

Titik, garis, bidang, dan ruang adalah contoh unsur-unsur primitif dalam geometri yang dapat diamati pada Lopo Boti. Setiap bagian memiliki filosofi yang berkaitan dengan ilmu matematika khususnya geometri. Konstruksi dari atap Lopo Boti menunjukkan adanya keterkaitan antara unsur titik, bidang, dan ruang. Konstruksi dari atap Lopo Boti ditunjukkan pada Gambar 5. 
DOI: https://doi.org/10.24127/ajpm.v9i3.2900

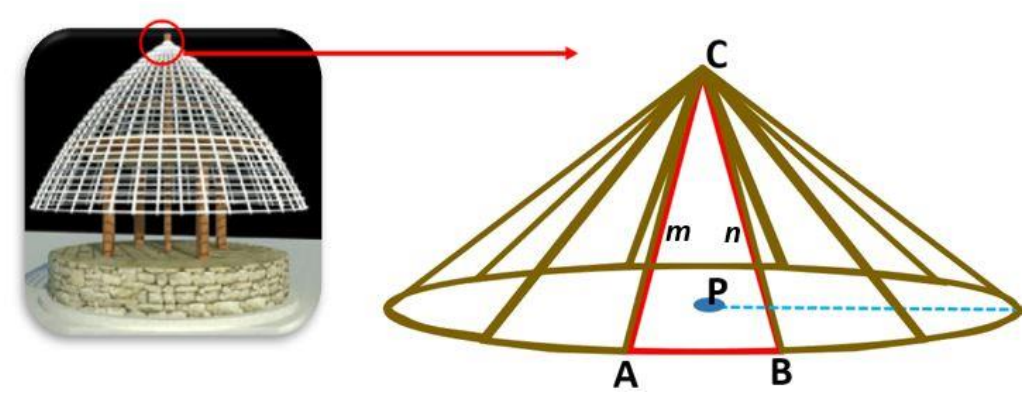

Gambar 5. Aksioma titik, garis, dan bidang pada kerangka atap Lopo Boti.

Pada Gambar 5 dapat dilihat bahwa jika kita misalkan perpotongan suaf $m$ dan suaf $n$ pada kerangka atap lopo dengan titik $C$, perpotongan suaf $m$ dengan lingkaran $P$ sebagai titik $A$, dan perpotongan suaf $n$ dengan lingkaran $P$ sebagai titik $B$ maka dapat dibentuk garis $A B$ yang melalui titik $A$ dan titik $B$, garis $B C$ yang melalui titik $B$ dan titik $C$, dan garis $A C$ yang melalui titik $A$ dan titik $C$. Ini menggambarkan aksioma titik dan garis yaitu suatu garis dapat dibentuk di antara dua titik yang berbeda.

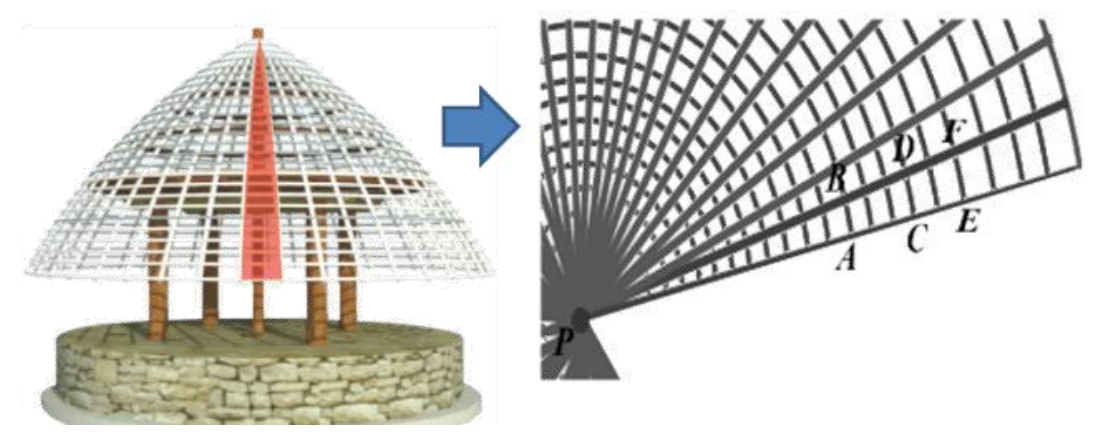

Gambar 6. Selimut kerucut pada kerangka atap Lopo.

Selain itu, berdasarkan aksioma garis dan bidang, suatu bidang $A B C$ dapat dibentuk dari ketiga garis tersebut karena titik $A, B$, dan $C$ tidak segaris. Konsep geometri lainnya yang terintegrasi pada kerangka atap lopo yaitu kesebangunan. Jika diperhatikan pada Gambar 6, perpotongan 25 lingkaran dengan suaf-suaf pada atal Lopo membentuk juring-juring lingkaran yang sebangun. Sebagai contoh, ada kerangka atap, $m(\angle A P B)=m(\angle C P D)$, sehingga jika $P A: P C=P B: P D$ maka juring $A P B$ dan juring $C P D$ sebangun.

\section{Tup Mahae dan Tobe}

Tup Mahae atau nyiru berkaki adalah tempat menyimpan makanan yang terbuat dari anyaman daun lontar dan memiliki kaki di setiap titik sudutnya (ditunjukkan pada Gambar 7).
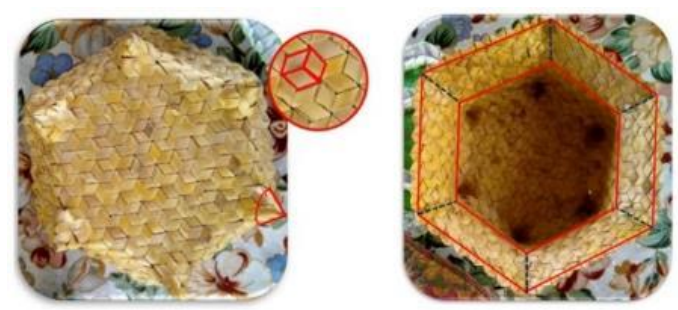

Gambar 7. Tup Mahae 
DOI: https://doi.org/10.24127/ajpm.v9i3.2900

Tup Mahae mengintegrasikan unsur-unsur geometri khususnya bidang datar dan bangun ruang. Tup Mahae berbentuk bangun gabungan yang terdiri dari 1 segienam beraturan dengan enam lingkaran di setiap titik sudutnya, 6 trapesium, 6 persegi panjang, 6 kerucut tanpa alas, dan 48 segitiga pada sisi atas tup mahae dengan 8 segitiga di setiap sisinya (ditunjukkan pada Gambar 8). Berdasarkan bangun-bangun penyusunnya, luas permukaan tup mahae dapat ditentukan dengan menghitung luas permukaan setiap bangun datar yang menyusun tup mahae tersebut dan menjumlahkan hasilnya yaitu:

$$
\begin{aligned}
& L_{\text {Tup Mahae }}=2 \cdot L_{A D C B}-6 \cdot \\
& L_{\text {Lingkaran }}+6 \cdot L_{A B G H}+6 \cdot \\
& L_{G H S I}+48 \cdot L \Delta+6 \cdot \\
& L_{\text {selimut kerucut }} \\
&= 2\left(\frac{1}{2}(A D+B C) \cdot t_{4}\right)-6\left(\pi r^{2}\right)+ \\
& 6(G H \cdot G A)+6\left(\frac{1}{2}(G H+S T) \cdot\right. \\
&\left.t_{1}\right)+48\left(\frac{1}{2} \cdot \tau \cdot t_{2}\right)+6(\pi r s) \\
&=(A D+B C) t_{4}+6(G H+G A)+ \\
& 3 t_{1}(G H+S T)+24 \tau t_{2}+6 \pi r\left(r^{2}+\right. \\
&\left.t_{3}{ }^{2}-r\right)
\end{aligned}
$$

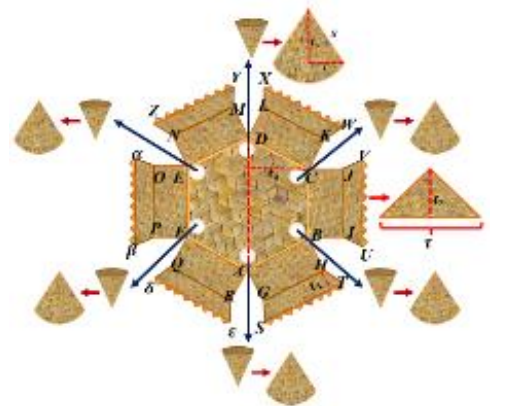

Gambar 8. Jaring-jaring Tup Mahae.

Sedangkan dari segi bangun ruang, sisi bagian dalam tup mahae dapat dipandang sebagai suatu prisma segienam (Gambar 9). Dengan menggunakan rumus volume prisma, volume Tup Mahae dapat ditentukan yaitu: $V=2\left(\frac{1}{2}(F C+E D) t_{1}\right) t_{2} \ldots$ (ii).

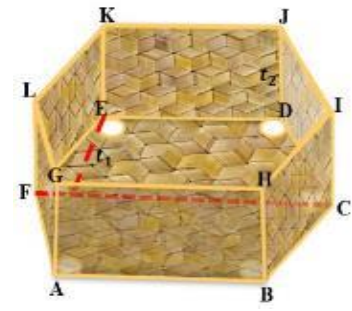

Gambar 9. Bagian dalam Tup Mahae berbentuk prisma segienam.

Artefak lainnya yaitu tobe atau tudung adalah penutup makanan yang terbuat dari anyaman daun lontar (Gambar 10). Baik tup mahae ataupun tobe dianyam menggunakan motif pep tenu atau tiga bagian (pep artinya bagian; tenu artinya tiga). Рер Тепu terdiri dari tiga buah segiempat yang saling berimpitan pada kedua sisinya membentuk bangun segienam.

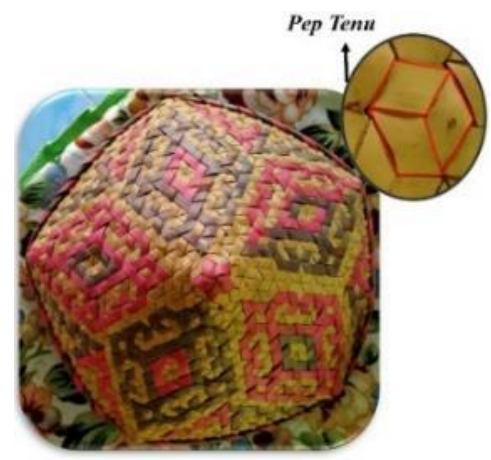

Gambar 10. Tobe.

Sama seperti Tup Mahae, Tobe atau tudung juga dapat dipandang sebagai bangun gabungan. Jika diperhatikan, tobe terbentuk dari limas segilima tanpa alas dan 65 segitiga, masing-masing 13 segitiga di setiap sisinya (Gambar 11). Dengan mengasumsikan bahwa kelima segitiga pada selimut tobe kongruen (begitu juga untuk 65 segitiga pada sisi luar tobe) maka luas permukaan tobe dapat dihitung dengan menjumlahkan luas bangun-bangun datar penyusunnya. 
DOI: https://doi.org/10.24127/ajpm.v9i3.2900

$$
\begin{aligned}
L_{\text {Tobe }}= & 5 \cdot L_{\text {Segitiga Besar }}+65 \cdot \\
& L_{\text {Segitiga Kecil }} \\
= & 5\left(\frac{1}{2} A B \cdot t_{1}\right)+65\left(\frac{1}{2} P Q \cdot t_{2}\right)= \\
& \frac{5}{2}\left(A B \cdot t_{1}+13 P Q \cdot t_{2}\right)
\end{aligned}
$$

Sedangkan, volume tobe dihitung menggunakan rumus volume limas segilima:

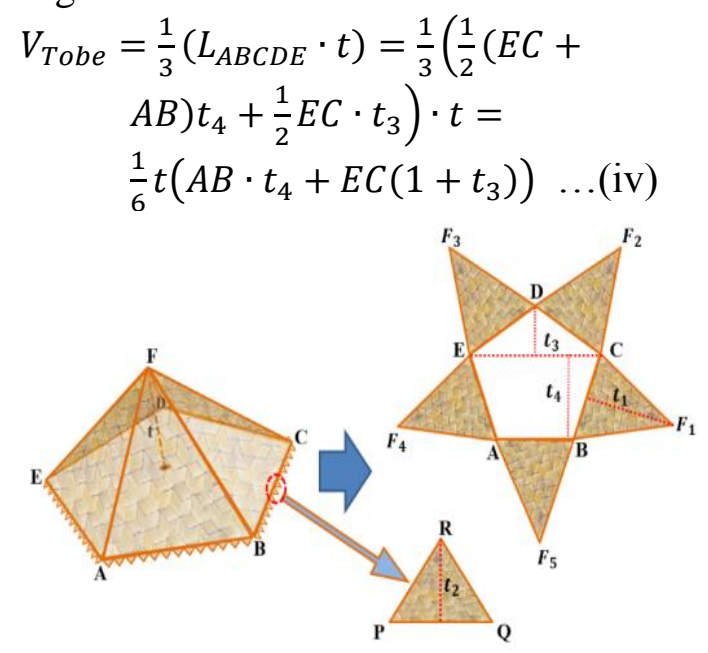

Gambar 11. Jaring-jaring tobe.

Sene

Di dalam lopo terdapat sembilan gong yang disebut sene dan digantung dengan pola tertentu. Kesembilan gong tersebut dipercaya sebagai gong pemanggil hujan yang mulai digantung di lopo ketika masa tanam tiba hingga akhir masa panen. Suku Boti percaya bahwa jika kesembilan gong tersebut dibunyikan maka hujan akan turun di daerah Boti. Apabila musim panen telah selesai maka kesembilan gong tersebut akan disimpan dan diganti dengan sembilan gong musim panas.

Kesembilan gong tersebut terbagi atas empat kelompok yang disusun sejajar, berturut-turut dari kiri ke kanan: (1) laban (dua gong yang paling kiri, disusun vertikal), (2) ote (dua gong di sebelah kanan laban, disusun vertikal), (3) kbolo (dua gong di sebelah kanan ote, disusun vertikal), dan (4) en-fenu (tiga gong paling kanan yang disusun

horizontal, setiap gongnya disebut enaf, karena lebih dari satu maka disebut enfenu). Gong-gong tersebut akan dimainkan bersama dengan tifa atau gendang yang terbuat dari kulit sapi ketika menjalankan ritual memanggil atau menghentikan hujan.

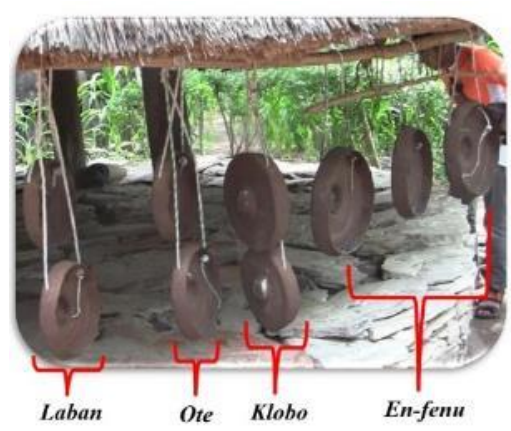

Gambar 12. Sene.

Sene mengintegrasikan konsep bangun datar dan bangun ruang. Konsep bangun datar terintegrasi melalui bagian permukaan sene yang berbentuk lingkaran, sedangkan konsep bangun ruang terintegrasi melalui bagian tengah sene yang berbentuk setengah bola dan selimut tabung yang mengelilingi badan sene. Berdasarkan bangun-bangun penyusunnya maka luas permukaan sene dapat ditentukan dengan rumus:

$$
\begin{aligned}
L_{\text {Sene }} & =\pi\left(r_{1}{ }^{2}-r_{2}{ }^{2}\right)+\frac{1}{2}\left(4 \pi r_{2}{ }^{2}\right)+2 \pi r_{1} t \\
& =\pi\left(r_{1}{ }^{2}+r_{2}{ }^{2}+2 r_{1} t\right) \quad \ldots(\mathrm{v})
\end{aligned}
$$

Di dalam lopo, sene digantungkan di salah satu sisi lopo menggunakan tali yang menyinggung sene di kedua sisinyat. Cara pemasangan sene ini mengintegrasikan konsep garis singgung lingkaran yaitu suatu garis yang memotong lingkaran di suatu titik yang disebut titik singgung dan tegak lurus terhadap jari-jari lingkaran yang melalui titik singgung tersebut. Konsep dari garis singgung lingkaran yang tercermin dari Sene dapat dilustrasikan seperti pada Gambar 13. Bentuk yang menyerupai gong pada umumnya namun menyimpan konsep matematika. 


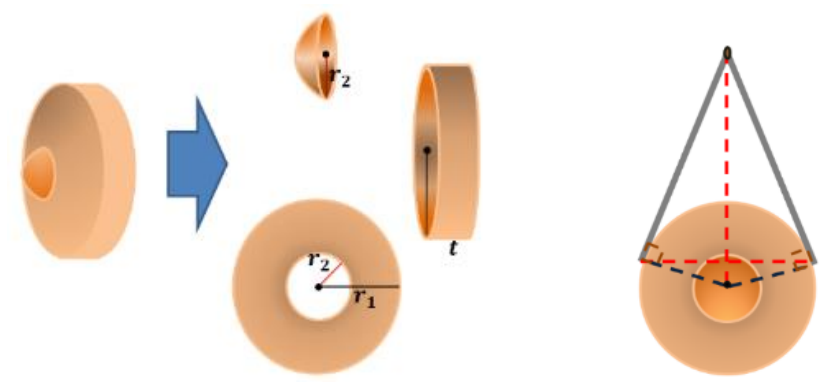

Gambar 13. Sene sebagai suatu bangun gabungan

Berdasarkan unsur-unsur matematika yang ada dalam Budaya suku Boti dan kaitannya dengan matematika sebagai ilmu maka beberapa kemampuan berikut ini dapat dikembangkan dalam pembelajaran matematika berbasiskan budaya suku Boti.

\section{Kemampuan Representasi}

Representasi adalah model atau bentuk pengganti dari situasi masalah yang ada untuk mengeksplorasi dan memecahkan masalah tersebut. Melalui representasi, ide-ide matematis dapat lebih dikonkritkan (Anwar \& Rahmawati, 2017). Pada artefak budaya suku Boti, kemampuan representasi siswa dapat dikembangkan melalui simbolisasi terhadap kondisi nyata dari artefak-artefak budaya Boti yang mengandung unsur-unsur geometri. Kemampuan ini diperlukan untuk menyelesaikan masalah-masalah seperti menentukan banyaknya segitiga yang sebangun pada jaring-jaring atap lopo.

\section{Kemampuan Visual Spasial}

Pembelajaran matematika berbasiskan budaya Suku Boti dapat melatih siswa dalam mengembangkan kemampuan spasialnya. Kemampuan visual spasial adalah kemampuan seseorang dalam mempersepsikan dunia visual dan mentransformasikannya ke dalam berbagai bentuk (Hariastuti, Anita, \& Setiawan, 2018). Kemampuan ini bisa dilatih dengan meminta siswa untuk menghitung banyaknya juring yang terdapat pada jaring-jaring atap lopo. Sebagai contoh, banyaknya juring yang dapat dibentuk dari perpotongan lingkaran paling atas dari 25 lingkaran pada kerangka atap dengan 5 suaf yang berdampingan dapat dihitung dengan membaginya dalam beberapa kasus dan menjumlahkan hasilnya seperti pada Gambar 14

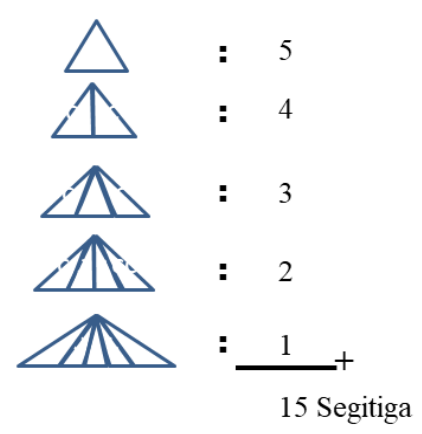

Gambar 14. Penghitungan banyaknya juring yang dibentuk oleh lingkaran paling atas pada kerangka atap dengan 5 suaf yang berdampingan. 
Kemampuan tilik ruang sebagai salah satu kemampuan visual spasial pun dapat dikembangkan melalui pengamatan terhadap artefak-artefak budaya suku Boti. Kemampuan ini meliputi kemampuan mengidentifikasi, mengklasifikasi, membandingkan, dan menganalisis karakteristik dari sifatsifat dan hubungan-hubungan pada bidang dan objek geometri satu, dua dan tiga (Yeni, 2011). Bangun gabungan seperti tup mahae, tobe, dan sene, apabila dilibatkan dalam pelajaran matematika, akan melatih para siswa dalam belajar menganalisis karakteristik dari bangun-bangun tersebut sebagai suatu bangun gabungan, mengidentifikasi bangun-bangun datar (serta bangun ruang) penyusunnya, dan bagaimana bangun-bangun tersebut terhubung berkaitan dengan konsep volume dan luas.

\section{Kemampuan Koneksi}

Kemampuan koneksi matematis adalah kemampuan menghubungkan konsep-konsep matematis baik antara antar konsep matematis itu sendiri, ataupun menghubungkan konsepkonsep matematis dengan konsepkonsep lainnya dan dunia nyata (Siregar \& Daut Siagian, 2019). Pembelajaran geometri berbasis budaya Boti akan membantu para siswa dalam belajar mengoneksikan konsep-konsep yang dipelajari dengan dunia nyata. Selain itu, siswa juga dapat belajar membangun konseksi antar konsep matematika, misalnya koneksi antara konsep geometri dan aljabar untuk menentukan ukuran salah satu unsur pada tup mahae jika luasnya diketahui. Dengan koneksi matematis, persepsi siswa akan diperluas sehingga konsep matematika dapat dipahami sebagai suatu kesatuan yang utuh dan tidak saling terpisah (Apriyono, 2016).

\section{Kemampuan Pemecahan Masalah}

Soal-soal pemecahan masalah matematis yang bersifat non rutin akan mendorong seseorang untuk mengembangkan kemampuan berpikir tingkat tingginya guna memecahkan masalah yang diberikan (Dosinaeng, Leton, \& Lakapu, 2019). Berkaitan dengan etnomatematika, Karinawati, Supriadi, \& Arisetyawan (2016), berdasarkan hasil penelitiannya, menjelaskan bahwa pembelajaran matematika berbasis etnomatematika Sunda berpengaruh positif pada kemampuan pemecahan masalah siswa Sekolah Dasar. Sejalan dengan itu, mengerjakan soal-soal berbasis budaya suku Boti seperti menghitung luas tup mahae dan tobe atau menentukan banyaknya juring sebangun yang dapat dibentuk pada jaring-jaring atap lopo akan membantu siswa dalam mengembangkan kemampuan pemecahan masalahnya sebab berkaitan dengan masalah dalam kehidupan sehari-hari dan tidak dapat diselesaikan hanya dengan langsung menerapkan rumus semata. Dibandingkan meminta siswa menentukan apakah dua juring sebangun atau tidak, menghitung banyaknya juring sebangun pada jaringjaring lopo akan memberikan pengalaman belajar yang berbeda bagi siswa.

\section{KESIMPULAN DAN SARAN}

Suku Boti adalah suku asli Timor yang kaya akan ragam budaya. Dari hasil eksplorasi ditemukan banyak konsep geometri yang terintegrasi pada lopo, tup mahae,tobe, dan sene. Konsep-konsep tersebut meliputi aksioma titik, garis, dan bidang, konsep garis singgung, konsep luas dan volume bangun datar, konsep luas dan volume bangun ruang, serta konsep kekongruenan. Selain itu, kemampuankemampuan matematis seperti 
kemampuan representasi, kemampuan visual spasial, kemampuan koneksi, dan kemampuan pemecahan masalah dapat dikembangkan berdasarkan unsur-unsur geometris pada budaya suku Boti. Hasil eksplorasi ini dapat digunakan oleh para guru matematika untuk mengembangkan pembelajaran geometri di kelas berbasis budaya Boti. Selain itu, penelitian lanjutan berupa pengembangan bahan ajar berbasis budaya suku Boti pun dapat dilakukan berdasarkan hasil penelitian ini. Diharapkan dengan menggunakan pendekatan etnomatematika ini, pembelajaran matematika di kelas dapat menjadi lebih menarik dan bermakna.

\section{DAFTAR PUSTAKA}

Abdullah, A. S. (2017). Ethnomathematics in Perspective of Sundanese Culture. Journal on Mathematics Education, 8(1), 116.

https://doi.org/10.22342/jme.8.1.38 77.1-15

Ambrosio, U. D. (1985). Ethnomathematics and its Place in the History and Pedagogy of Mathematics. (February), 44-48.

Andung, P., \& Nope, H. (2017). Media Rakyat sebagai Media Komunikasi Pembangunan Masyarakat Suku Boti. Jurnal Ilmu Komunikasi, 14(2), 277-292. https://doi.org/10.24002/jik.v14i2. 870

Anwar, R. B., \& Rahmawati, D. (2017). Symbolic and Verbal Representation Process of Student in Solving Mathematics Problem Based Polya's Stages. International Education Studies, 10(10), 20. https://doi.org/10.5539/ies.v10n10 p20

Apriyono, F. (2016). Profil Kemampuan Koneksi Matematika Siswa SMP dalam Memecahkan Masalah Matematika Ditinjau dari Gender. Jurnal Mosharafa, 5(2), 159-168.

Dosinaeng, W. B. N. (2017). Analisis pemikiran matematis dalam permainan tradisional masyarakat lamaholot. Prosiding Seminar Nasional Etnomatnesia, 491-498.

Dosinaeng, W. B. N., Leton, S. I., \& Lakapu, M. (2019). Kemampuan Mahasiswa dalam Menyelesaikan Masalah Matematis Berorientasi HOTS. JNPM (Jurnal Nasional Pendidikan Matematika), 3(2), 250.

https://doi.org/10.33603/jnpm.v3i2 .2197

Fouze, A. Q., \& Amit, M. (2018). Development of Mathematical Thinking through Integration of Ethnomathematic Folklore Game in Math Instruction. EURASIA Journal of Mathematics, Science and Technology Education, 14(2), 617-630.

https://doi.org/10.12973/ejmste/80 626

Ghony, M. D., \& Almanshur, F. (2014). Metodologi Penelitian Kualitatif. Jogjakarta: Ar-Ruzz Media.

Hariastuti, Rachmaniah M, Anita, D., \& Setiawan, M. A. (2018). Pengembangan Media Geo-Sd (Geometri Sketsa Dimensi) Sebagai Penunjang Kemampuan Visual Spasial. AKSIOMA: Jurnal Program Studi Pendidikan Matematika, $\quad 7(1), \quad 10$. https://doi.org/10.24127/ajpm.v7i1. 1234 
DOI: https://doi.org/10.24127/ajpm.v9i3.2900

Hariastuti, Rachmaniah Mirza, Budiarto, M. T., \& Manuharawati, M. (2019). From Culture to Classroom: Study Ethnomathematics in House of Using Banyuwangi. International Journal of Trends in Mathematics Education Research, 2(2), 76. https://doi.org/10.33122/ijtmer.v2i 2.60

Karinawati, A., Supriadi, \& Arisetyawan, A. (2016). Pengaruh Pembelajaran Etnomatematika Sunda Terhadap Kemampuan Pemecahan Masalah Matematis Siswa Sekolah Dasar. Kalimaya, 4(2).

https://doi.org/10.1023/A:1015237 612018

Maryati, \& Prahmana, R. C. I. (2019). Ethnomathematics: Exploration of the muntuk community. International Journal of Scientific and Technology Research, 8(6), 47-49.

Muhtadi, D., Sukiran, Warsito, \& Prahmana, R. C. I. (2017). Sundanese Ethnomathematics: Mathematical Activities in Estimating, Measuring, and Making Patterns. Journal on Mathematics Education, 8(2), 185198.

https://doi.org/http://dx.doi.org/10. 22342/jme.8.2.4055

Nuban, D. K. E. R., Hartiwiningsih, \& Jamin, M. (2017). The Legal Aspects of Boti's Tribe: "When the National Law is not Required." International Journal of Business, Economics and Law, 13(4), 130137.
Purnama, W., \& Rohmah, M. S. (2018). Sejarah dan Filsafat Matematika (Edisi Revisi 2018). Direktorat Jenderal Guru dan Tenaga Kependidikan,Kementerian Pendidikan dan Kebudayaan.

Sandiningtyas, H., \& Wiyono, B. B. (2018). Pendidikan Berbasis Budaya Lokal Suku Boti: Studi Kasus di SDN-SMPN Satu Atap Oefau Desa Boti Nusa Tenggara Timur. Ilmu Pendidikan: Jurnal Kajian Teori Dan Praktik Kependidikan, 3, 77-82.

Siregar, R., \& Daut Siagian, M. (2019). Mathematical Connection Ability: Teacher's Perception and Experience in Learning. Journal of Physics: Conference Series, 1315(1). https://doi.org/10.1088/17426596/1315/1/012041

Suminar, E. (2018). Persepsi Suku Boti Terhadap Lingkungan Hidup. Ensains Journal, 1(2), 89. https://doi.org/10.31848/ensains.v1 i 2.100

Supriadi, S., Susilawati, S., \& Tristyanto, B. (2019). Ethnomathematics in Mathematics, Social and Physical Education. Journal of Physics: Conference Series, $1318(1)$. https://doi.org/10.1088/17426596/1318/1/012126

Utami, N. W., Sayuti, S. A., \& Jailani. (2019). Math and Mate in Javanese Primbon: Ethnomathematics Study. Journal on Mathematics Education, 10(3), 341-356. https://doi.org/10.22342/jme.10.3.7 611.341-356 
DOI: https://doi.org/10.24127/ajpm.v9i3.2900

Yeni, E. M. (2011). Pemanfaatan Benda-Benda Manipulatif Untuk Meningkatkan Pemahaman Konsep Geometri dan Kemampuan Tilik Ruang Siswa Kelas V Sekolah Dasar. (1), 63-75.

Yustinaningrum, B., Nurliana, \& Rahmadhani, E. (2018). The ethnomathematics: Exploration of Gayo tribe local wisdom related to mathematics education. Journal of Physics: Conference Series, 1088. https://doi.org/10.1088/17426596/1088/1/012061
Zaenuri, Dwidayati, N., \& Suyitno, A. (2019). Ethnomathematics Role As an Encouragement of the Growth of Student's Nationalism. KnE Social Sciences, 2019, 759-774. https://doi.org/10.18502/kss.v3i18. 4766 